\title{
THE MECHANICAL WORK OF THE TWELFTH CENSUS.
}

Now that the Census Bureau has been made a permanent branch of the government, it attains the dignity and importance which its merits deserve. A popular impression prevailing among a large number of people is that the main part of the work of the Census is the taking of it, that is to say, the gathering of the ata. That nothing could be more erroneous is evidenced by the fact that by legislative enactment a single month only was allowed for the taking of the Twelfth Census, while two years were given within which to tabulate the data. The data collected can have no meaning or. value to the legislator and the student of sociology and political economy until classified into categories which form a basis for comparisons and conclusions. This is the real work of the Census Bureau, and it is of enormous proportions. The last decade of the nineteenth century added to the wealth of our country, according to Mulhall, twentyfive billion dollars, which is estimated to be more than the nation was able to save from the discovery by Columbus to the breaking out of the civil war. It also added immensely to the growth of our country in productive resources, in population and in problems sociological and economic. Upon undertaking their work therefore the officials of the Twelfth Census found confronting them such a demand for further data and more light affecting these interests, that new and extraordinary instrumentalities were invoked to shorten the labor, extend the tabulations, and increase the accuracy, speed, and effectiveness of the clerical force in separating, segregating, and classifying into categories the vast amount of data. The machine has been adapted to this work and made to take the place of the erring eye, the faulty memory, or the careless hand to such an extent that Yo-day the Census Office rresents the appearance and busy hum of a vast machine shop rather than that of a great counting-house Electricity has lent its expedition and subtle force to supplement human service, and the clerical work, largely emancipated from the errors of the personal equation, is brought under the control of physical laws. Facts and figures have thus within an incredibly short space of time been presented in such an array of categories and permutations as to give the student quick and convenient indent aurck and sight as to what this avalanche of figures means and what prophecy and suggestion they hold for the future. It is a splendid tribute to the executive ability of Director Merriam and to the experience and foresight of Chief Statisticians Powers, of Chief Statisticians Powers,
King, and Hunt, as well as evidence of the value of the in-

vention as a factor in the world's work. flite $\mathrm{Hol}$ lerith system of mechanical punching and tabulation had its inception in the preceding census $/$ and its fundamental principles and instrumentalities were described and illustrated in the issue of this paper of August 30, 1890. Whe system, however, has been greatly improved and extended to meet the larger want of the present time. The two main features of the system are, first, a punched card, and, secondly, means for transferring its legend mechanically to registers which classify it into groups or categories and add the units thereof to form sum totals for the groups The punched card varies somewhat in size and shape according as it is for population or agriculture. Generally speaking, it is from 5 to 7 inches long and 3 inches wide, and until its values are explained and un derstood it is a very insignificant and blind piece of paste-board. It stands between the enumerator's return sheet and the tabulating machine, and is the neans by which the tabulating machine is made to mechanically discriminate in classifying the data borne by the card into groups, classes, or categories. The punchings in the card are not for the purpose of a public record, but are intermediary instrumentalities and the positions of the punched holes in the card mean everything to the tabulating machine. By the special location of a hole within the limits of certain boundary lines on the card it means one thing, and in another position it means another thing, and it is this position of a punched hole in a card that enables the tabulating machine to afterward transfer the value of that particular position of a hole on the card to a gang of counters and registers classifying the data into groups and adding the totals. It is done in this way: The card having been punched with holes to signify by their positions on the card the information contained on the written enumerator's schedule, the said card is put in a tabulating machine, where it act as a stop diaphragm between a multiplicity of little spring-seated pins above the card and a correspondins series of mercury cups below the card. The pins are now, in a group, brought down, and those which are in line with holes in the card will descend through sai holes and, by touching the mercury below, will close so many separate electric circuits. Those pins which do not find holes in the card below them do not pass to contact with the mercury and do not close their individual electric circuits. Each pin and its mercury cup are terminals of a separate electric circuit passin through an electro-magnet controlling a counter or resister. The pins are carried in a frame known as a pinbox. It will thus be seen that the so-called pin-box is a sort of electric permutation circuit controller, and that the circuit closed through any one counter or register will be determined by one position of a hole in a card, and another circuit through another counter by another position of a hole. This gives the machine mechanical selective action and constitutes its mode of thinking, as it were.

There are two kinds of punching machines. One is for population and the other for farms. In the farm punch the card is automatically moved through the machine under the punches, which correspond in number to the ten numerals, with one extra punch. In the population punch the card is held fixedly in a holder, and a swinging lever arm bears at the handle end a position-finding stylus, which has below it a large keyboard of holes exactly corresponding in number, position, and grouping with the number, position, an grouping borne by the blank card. When the stylus is depressed into a certain hole in the key-board a punch, about mid-way of the lever, finds and punches hole in the exact spot on the card corresponding to the hole on the key-board into which the stylus was depressed. Simpler and more recent is the farm card. In punching the spaces indicating dollars the unit are, for economy sake, disregarded; thus 400 mean $\$ 4,000 ; 150$ means $\$ 1,500$, and so on. The three columns to the left of the card simply divide the farm their incomes and products, into ten groups, the first column giving ten sizes of farms, the second givin

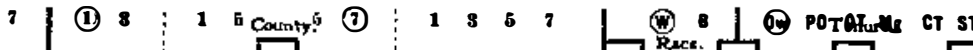
(1)
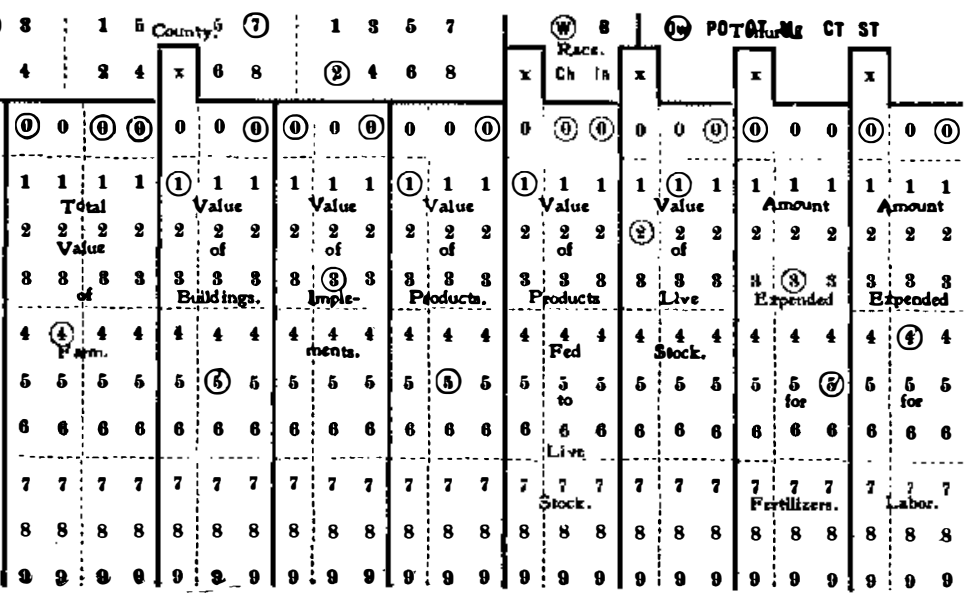

A FARM CARD, AS USED IN CENSUS CALCULATING MACHINE.

ten sources of income, and the third ten sizes of income, which are arbitrarily indicated by the figure and interpreted by an explanatory key.

The card having been punched, is then placed in tabulating machine. The front view of a group of four tabulating sections shows the pin-box, and the handle for raising and lowering it being shown on the right. The rear view illustrates the quadrantal segments of electro-magnets arranged in rear and above the adding wheels. This view shows also the multiplicity of electric cables connected to the magnets an leading to the pin-box. It is not practicable within th limits of space available to describe in detail the tab ulating and adding devices. It must suffice to say that a punched card is placed below the pin-box on the subjacent table surface bearing the mercury cup shown on the right of Fig. 5, and, the pin-box being brought down by the operator by means of the handle bar, the card automatically selects its counters or adding wheels as hereinbefore described. To explain how the machine adds, i. e., how a group of units is at on operation transferred to the adding wheel, reference is made to the rear view. For each adding device there is a quadrantal series of nine electro-magnets a ranged in an arc about the adding wheels. A radia arm oscillates or swings about the center of the adding wheels, and in its sweep a pawl carried by it is made to turn the adding wheels any number of spaces according to the number to be added. This is accomplished by causing the turning pawl of the swing arm to act on the adding wheel sooner or later in the swee of the arm. If it acts immediately on starting it turn the adding wheel nine spaces and adds 9 . If it does not act until it has passed the fifth magnet it turn the wheel four spaces and adds 4 . The timing of the action of the pawl on the adding wheel as the arm sweeps over the same is effected by the segmenta series of electro-magnets as follows: Each magnet is sonnected to the electrodes of the pin-box, and the selection of a particular magnet in the curved series is controlled by the selective action of the punched card at the pin box, which is made to close a circuit through any one of the magnets of the curved segment. Such magnet when energized is made to release ing arm and striking an attachment thereon, causes the turning pawl of the swinging arm to engage an adding wheel and turn it a greater or less number of spaces according to the position of the magnet in the segmental series which has been energized.

A card to be tabulated on one of these machines is box, the pin-box depressed and the card then removed by hand. If the card is properly tabulated a little bell rings simultaneously with the depression of the pinbox. If a card has not been properly punched, the machine gives notice of the same so that the error may be corrected. When the card is removed, it is placed by the operator's hand in one of a series of comfacilitate this work the pin-box is made, through electrical connections, to automatically open the proper door of the compartment into which the card is to be stored.

There are five different kinds of punched cards used in the work of the Census Office. In the agricultural illustrated, another card known as the crop card. In the population and vital statistics divisions there are three different cards, namely, the individual card, the family card, and the mortality card. In round numbers there have been employed in the whole work of the census something over $6,000,000$ farm cards, $115,000,000$ crop cards, 76,000,000 individual cards, $16,000,000$ famnumber of farm cards mortality cards. The average described was, for the month of June, 1901, a little over 5,000 daily. This average has subsequently been raised to over 8,000 daily. The crop cards are handled more expeditiously, and 10,000 is the daily average. The division of agriculture employs twelve of the large farm-card machines and eightychines.

The latest development of the Hollerith System is the automatic machine, in which the work of separately placing each card beneath the pin-box, depressing the pin-box, and removing the card, is performed automatically by a machine instead of by hand. This automatic machine is operated by an electric motor supplied by current from the cable overhead. The cards are fed in a bunch to the top of the machine, the pin-box occupies a vertical instead of a horizontal plane, and the mercury cups are replaced by spring jacks. The machine itself successively feeds each card to the pin-box or circuit controller and tabuates its data automatically. If an improperly punched or distorted card happens to be in the lot it is automatically thrown out into a special receptacle for it, while the properly registered cards go to their own compartments. These machines have been used experimentally in the census work, and the following has been reported as the result of tests, viz., that in six and a half hours 87,000 cards were tabulated on 27 counters, forty to fifty minutes of which time was occupied in taking the readings from the counters. In the automatic machine there is one man to feed the cards in bulk and one man to take the readings from the counters, but each of these men may perform this service for a number of machines. It is estimated that the automatic machine is capable of doing at least six times the work of the hand machine.

For courtesies received in gathering the foregoing ata thanks are due to Dr. LeGrand Powers, Chief of the Agricultural Division of the Census Office.

\section{The Current Supplement.}

Mr. Randolph I. Geare's article, "From Raft to Steamship," is continued in the current Supplement, No. 1372. The third part of this interesting discussion is devoted to modern sailing ships, and is well illustrated by half-tones representing standard types. E. Price-Edwards concludes his article on "Sound Signals." "Some Notes on Steam Turbines" is the title of an illustrated paper by F. J. Warburton, in which a most important phase of modern steam engineering is treated. The account of the Paris Automobile Show, begun in last week's Supplement, is concluded. A. D. Elbers contributes a most important article on "Tests and Constitution of Portland Cement." Coming as it does from a writer who has given no little thought to the subject, the article should be of wide interest. Among minor articles may be mentioned an account of the work at the World's Fair, city of St. Louis, "Texas Oil for Locomotive Fuel," "Lumière Process of Color Photography," and "Pressure of Luminous Rays." 


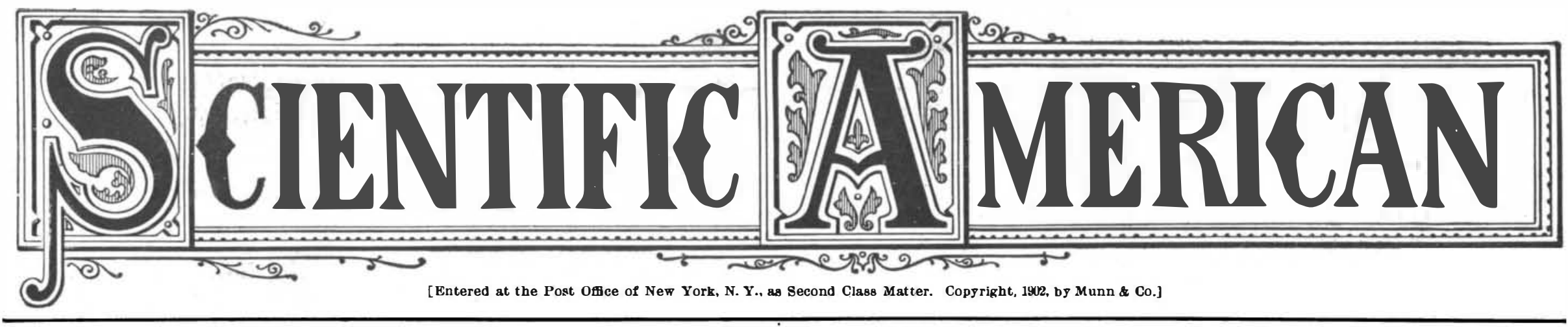

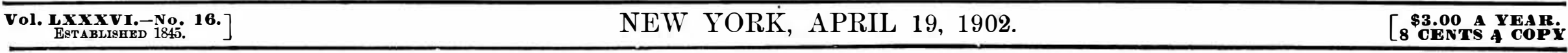

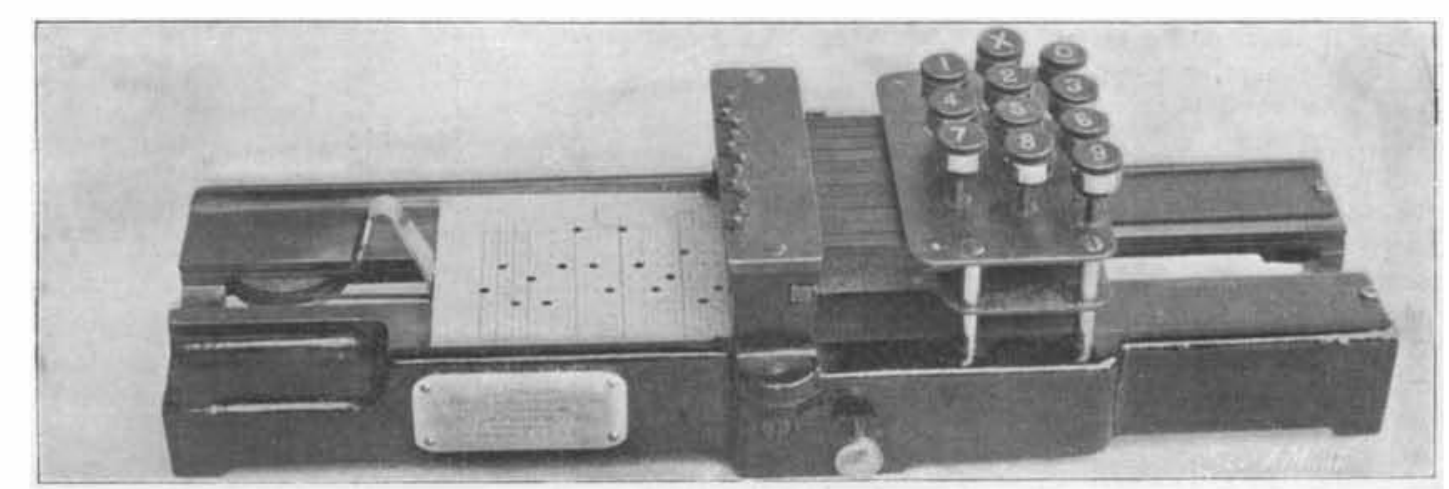

The Hollerith Card-Puncher.

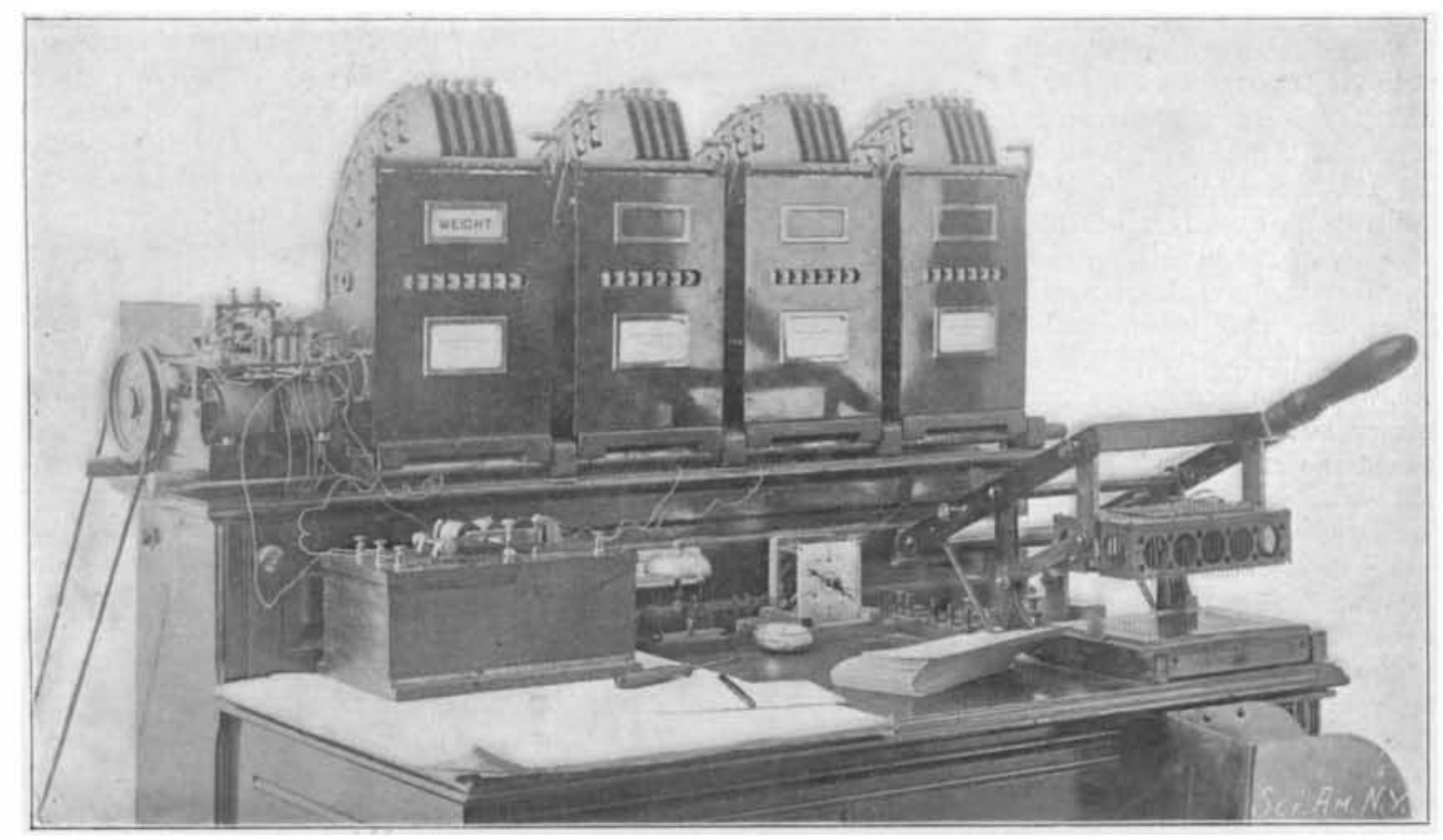

Front of Tabulating and Adding Machine.

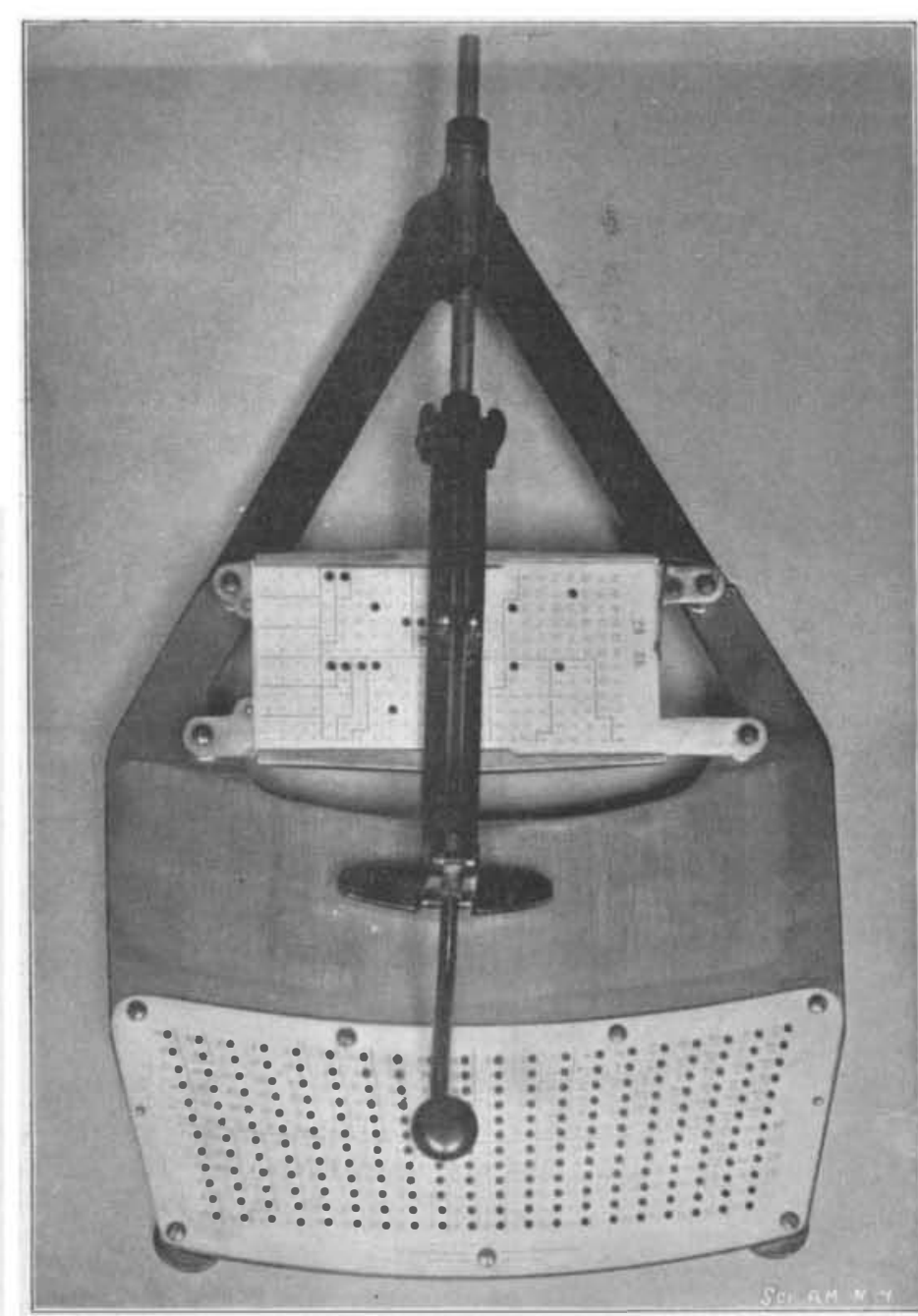

Population-Card Punch.
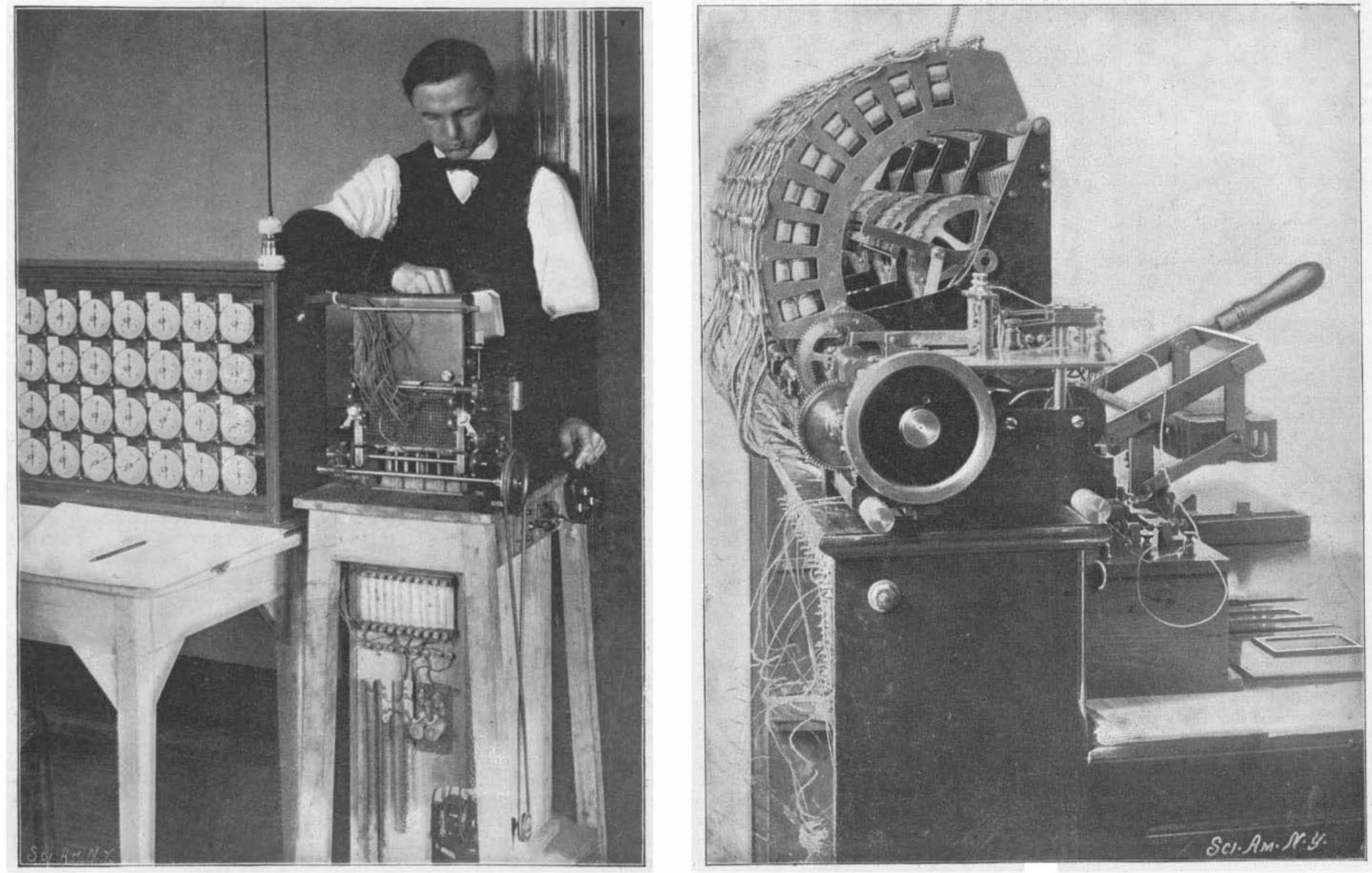

Automatic Tabulating-Machine.

Rear of Tabulating and Adding Machine. 